\title{
Increasing palmitic acid intake enhances milk production and prevents glucose-stimulated fatty acid disappearance without modifying systemic glucose tolerance in mid-lactation dairy cows
}

\author{
A. T. Mathews, ${ }^{*}$ J. E. Rico, ${ }^{*}$ N. T. Sprenkle, ${ }^{*}$ A. L. Lock, $\dagger$ and J. W. McFadden ${ }^{* 1}$ \\ *Division of Animal and Nutritional Sciences, West Virginia University, Morgantown 26506 \\ †Department of Animal Science, Michigan State University, East Lansing 48824
}

\begin{abstract}
Feeding saturated fatty acids may enhance milk yield in part by decreasing insulin sensitivity and shifting glucose utilization toward the mammary gland. Our objective was to evaluate the effects of palmitic acid (C16:0) on milk production and insulin sensitivity in cows. Twenty multiparous mid-lactation Holstein cows were enrolled in a study consisting of a 5 -d covariate, 49-d treatment, and 14-d posttreatment period. All cows received a common sorghum silage-based diet and were randomly assigned to a diet containing no supplemental fat (control; $\mathrm{n}=10 ; 138 \pm 45 \mathrm{~d}$ in milk) or C16:0 at $4 \%$ of ration DM (PALM; 98\% C16:0; $\mathrm{n}=10 ; 136 \pm$ $44 \mathrm{~d}$ in milk). Blood and milk were collected at routine intervals. Intravenous glucose tolerance tests $(300 \mathrm{mg} /$ $\mathrm{kg}$ of body weight) were performed at $\mathrm{d}-1,24$, and 49 relative to start of treatment. Data were analyzed as repeated measures using a mixed model with fixed effects of treatment and time, and milk yield served as a covariate. The PALM treatment increased milk yield by wk 7 . Furthermore, PALM increased milk fat yield and energy-corrected milk at wk 3 and 7 . Changes in milk production occurred in parallel with enhanced energy intake. Increased milk fat yield during PALM treatment was due to increased C16:0 and C16:1 incorporation; PALM had no effect on concentration of milk components, BW, or body condition score. Two weeks posttreatment, energy-corrected milk and milk fat yield remained elevated in PALM-fed cows whereas yields of milk were similar between treatments. Increased milk fat yield after PALM treatment was due to increased de novo lipogenesis and uptake of preformed fatty acids. The basal concentration of nonesterified fatty acids (NEFA) in plasma increased by d 4, 6, and 8 of PALM treatment, a response not observed thereafter. Although PALM supplementation did not modify in-
\end{abstract}

Received April 8, 2016.

Accepted August 1, 2016.

${ }^{1}$ Corresponding author: JWMcFadden@mail.wvu.edu sulin, glucose, or triacylglycerol levels in plasma, total cholesterol in plasma was elevated by wk 3 . Estimated insulin sensitivity was lower during the first week of PALM treatment; however, glucose disposal following glucose tolerance tests was not modified. In contrast, C16:0 feeding reduced glucose-stimulated NEFA disappearance by wk 7 . Results demonstrate that increasing dietary energy from C16:0 for 7 wk improves milk yield and milk composition without modifying systemic glucose tolerance. Reduced glucose-stimulated NEFA disappearance with C16:0 feeding and elevated circulating NEFA may reflect changes in adipose tissue insulin sensitivity.

Key words: dairy cow, insulin sensitivity, lactation, palmitic acid

\section{INTRODUCTION}

Dairy cows experience an elevated demand for circulating glucose at the onset of lactation due to an increased requirement by the mammary gland for lactose synthesis (Bell, 1995). As a means to partition glucose toward the mammary gland, early-lactation cows will develop insulin resistance to decrease glucose uptake by skeletal muscle and adipose tissues (Bell and Bauman, 1997; De Koster and Opsomer, 2013). Concomitantly, adipose tissue lipolysis will provide nonesterified fatty acids (NEFA) for $\beta$-oxidation in peripheral tissues and re-esterification in the mammary gland (McNamara and Hillers, 1986; Zachut et al., 2013). Because insulin is an antilipolytic hormone, insulin resistance can further facilitate the mobilization of NEFA from adipose tissue. These homeorhetic adaptations are characteristic metabolic shifts in energy metabolism that develop in early-lactation cows coping with energy insufficiency and increased milk production. As lactation progresses beyond peak daily milk yield, circulating insulin and insulin-stimulated glucose uptake by peripheral tissues increases, and basal NEFA availability declines to minimal levels (McNamara and Hillers, 1986; Bell and Bauman, 1997). Furthermore, the restoration of posi- 
tive energy balance is accompanied by the beginning of milk production decline.

The supplementation of SFA is a nutritional management practice used by producers to increase the energy density of diets offered to cows during lactation; however, the published production responses to palmitic acid feeding are variable. For instance, feeding cows palmitic acid (C16:0) has been reported to improve feed efficiency (Rico et al., 2014a) and increase milk yield and milk fat yield without reducing DMI (Piantoni et al., 2013) as compared with a no supplemental fat control. Feeding C16:0 at 1 to $4 \%$ of ration DM has resulted in gains of milk and milk fat yield ranging from 0.8 to 3.3 and 0.08 to $0.40 \mathrm{~kg} / \mathrm{d}$, respectively (Mosley et al., 2007; Wang et al., 2010; Piantoni et al., 2013; Rico et al., 2014b). In contrast, Rico et al. (2014a) fed bSTadministered mid-lactation cows a fatty acid supplement (85\% palmitic acid) at $2 \%$ of diet DM for $21 \mathrm{~d}$ and observed suppressed DMI with no change in milk yield. Similarly, feeding early-lactation cows palmitic acid at a comparable feeding level $(450 \mathrm{~g} / \mathrm{d})$ failed to significantly increase milk yield (Warntjes et al., 2008). Inconsistencies in milk production and DMI responses to C16:0 are likely due to differences in study design, including C16:0 feeding level, stage of lactation, length of treatment, and energy level of the experimental control. Supplementing C16:0 clearly increases the energy density of diets fed to cows; however, favorable lactation outcomes may not completely depend on the energy content of the supplemental C16:0. For instance, C16:0 feeding increases ECM and 3.5\% FCM when compared with C18:0 supplementation (Rico et al., 2014b).

Supplementing mid-lactation cows with C16:0 can influence metabolic health status, albeit moderately (Pires et al., 2007; Piantoni et al., 2013; Rico et al., 2014b). An increase in circulating NEFA with C16:0 supplementation is a consistent observation relative to C18:0 (Rico et al., 2014b) or without supplemental fat (Piantoni et al., 2013). Also, an elevation in plasma insulin coincides with an increase in C16:0 availability both at the basal level and during a glucose challenge (Pires et al., 2007; Piantoni et al., 2013). To our knowledge, the effects of high-purity C16:0 feeding on insulin sensitivity measurements in mid-lactation cows are limited to a single study (Piantoni et al., 2013). Although Piantoni et al. (2013) did not document any changes in glucose or insulin tolerance in mid-lactation cows supplemented with $\mathrm{C} 16: 0$ at $2 \%$ of diet DM for $21 \mathrm{~d}$, the effects of C16:0 provided at a greater dietary level for an extended duration on estimated insulin sensitivity, glucose tolerance, and glucose-stimulated NEFA disappearance have not been characterized. In monogastric animals, SFA antagonize insulin action in adipose and skeletal muscle tissues by inhibiting insulin-stimulated protein kinase B activation (Summers, 2006; Zachut et al., 2013), a response that is accompanied by the accrual of ceramide (Summers, 2006). Interestingly, insulin-resistant early-lactation cows experience an elevation in circulating $\mathrm{C} 16: 0$ and ceramide (Contreras et al., 2010; Rico et al., 2015). Because the availability of lipolysis-derived C16:0 declines with the progression of lactation, an increase in C16:0 availability in circulation and tissues may be a means of restoring homeorhetic nutrient partitioning to increase milk production. The magnitude of glucose intolerance may depend on C16:0 availability; therefore, our objective was to continuously characterize the effects of extended C16:0 supplementation on milk production outcomes, metabolic status, and response to a glucose challenge in mid-lactation dairy cows. We hypothesized that supplementing C16:0 at a high dietary level for a prolonged duration would increase milk and milk fat yield, and decrease insulin sensitivity.

\section{MATERIALS AND METHODS}

\section{Experimental Design}

Experimental procedures were approved by the Institutional Animal Care and Use Committee at West Virginia University (Morgantown). Twenty multiparous, mid-lactation Holstein cows were enrolled into the study completed at the West Virginia University Animal Science Farm. Cows were housed in a freestall barn and trained to access feed from Calan gate feeders (American Calan Inc., Norwood, NH). Diets were mixed and offered twice daily. Access to feed was blocked from 0800 to 1000 and 1600 to $1700 \mathrm{~h}$ to allow for orts and feed offered to be weighed. Cows were fed at $110 \%$ of expected intake, adjusted daily, and provided free access to water.

All cows received a common TMR for $14 \mathrm{~d}$ before experimentation. Following a 5 -d covariate period, cows were grouped by DIM and milk yield $(136 \pm 43$ DIM, $24.8 \pm 4.9 \mathrm{~kg}$ of milk/d), and offered a similar TMR consisting of no added fat (control; soyhull pellets; $\mathrm{n}=$ 10) or supplemented with C16:0 (PALM; Palmit 98; Global Agri-Trade, Long Beach, CA; $\mathrm{n}=10)$ at $4 \%$ ration DM for $49 \mathrm{~d}$. Posttreatment, all cows were fed the control diet without supplemental fat for $14 \mathrm{~d}$. Diets provided were composed of sorghum silage and alfalfa haylage as the main forage components and were formulated to meet or exceed nutrient recommendations (Table 1; NRC, 2001). Forages and concentrates were collected weekly, stored at $-20^{\circ} \mathrm{C}$, and composited at trial completion. 
Basal blood collection $(10 \mathrm{~mL})$ by coccygeal venipuncture occurred at $0600 \mathrm{~h}$ on $\mathrm{d}-3,-2$, and 0 of the covariate period and d 4, 6, 8, 14, 17, 21, 22, 24, 31, 38, 47 , and 49 of the treatment period. Although treatment ceased on d 49, additional basal blood samples were collected at $0600 \mathrm{~h}$ on $\mathrm{d} 52,56,62$, and 63 , relative to the initiation of treatment to characterize the posttreatment period. Blood was kept on ice for $30 \mathrm{~min}$ until centrifugation at $3,400 \times g$ for $10 \mathrm{~min}$. Following centrifugation, EDTA-preserved plasma was removed and stored at $-80^{\circ} \mathrm{C}$ until further analysis.

Cows were milked twice daily at 0800 and $1800 \mathrm{~h}$. Milk yield was continually recorded and milk samples were obtained at each milking on $\mathrm{d}-5,-4,20,21$, $45,46,62$, and 63 relative to the start of treatment. One milk aliquot was stored with bronopol at $4^{\circ} \mathrm{C}$ for component analysis and 1 additional aliquot was stored at $-20^{\circ} \mathrm{C}$ with no preservative for determination of fatty acid composition. Cows were weighed and scored

Table 1. Ingredients and nutrient composition of experimental diets supplemented with palmitic acid (PALM; C16:0) and control (no added fat)

\begin{tabular}{|c|c|c|}
\hline \multirow{2}{*}{$\begin{array}{l}\text { Item }(\% \text { of DM unless } \\
\text { otherwise noted) }\end{array}$} & \multicolumn{2}{|c|}{ Treatment } \\
\hline & Control & PALM \\
\hline \multicolumn{3}{|l|}{ Ingredient } \\
\hline Sorghum-sudangrass silage & 30.3 & 30.1 \\
\hline Ground corn & 29.1 & 28.9 \\
\hline Alfalfa haylage & 15.7 & 15.5 \\
\hline Soybean meal & 11.4 & 11.3 \\
\hline Soyhulls & 6.60 & 3.60 \\
\hline Beet pulp pellets & 2.90 & 2.80 \\
\hline Vitamin and mineral premix ${ }^{1}$ & 0.63 & 0.60 \\
\hline Protein blend $^{2}$ & 1.60 & 1.60 \\
\hline Sodium bicarbonate & 0.97 & 0.94 \\
\hline Zeolite & 0.48 & 0.47 \\
\hline Limestone & 0.32 & 0.29 \\
\hline C16:0-enriched fat supplement ${ }^{3}$ & 0.00 & 3.90 \\
\hline \multicolumn{3}{|l|}{ Nutrient composition } \\
\hline DM (\%) & 59.6 & 59.8 \\
\hline $\mathrm{CP}$ & 17.8 & 17.3 \\
\hline $\mathrm{NDF}$ & 33.6 & 31.6 \\
\hline Forage NDF & 24.8 & 24.8 \\
\hline Starch) & 21.7 & 21.6 \\
\hline Ether extract & 2.80 & 6.70 \\
\hline Ash & 12.6 & 13.1 \\
\hline $\mathrm{NE}_{\mathrm{L}}(\mathrm{Mcal} / \mathrm{kg}$ of DM) & 1.40 & 1.50 \\
\hline
\end{tabular}

${ }^{1}$ Vitamin-mineral mix contained $14 \% \mathrm{Ca}, 9.5 \% \mathrm{P}, 6.3 \% \mathrm{Mg}, 0.13 \% \mathrm{~K}$, $0.78 \% \mathrm{~S}, 4 \% \mathrm{Na}, 17.6 \% \mathrm{C}$, and (per $\mathrm{kg}$ ) $4,282 \mathrm{mg}$ of $\mathrm{Fe}, 3,000 \mathrm{mg}$ of $\mathrm{Zn}, 590 \mathrm{mg}$ of Cu, 1,600 $\mathrm{mg}$ of Mn, $62 \mathrm{mg}$ of Se, $53 \mathrm{mg}$ of $\mathrm{Co}$, and 31 $\mathrm{mg}$ of I, as well as $507 \mathrm{kIU}$ of vitamin A, $69 \mathrm{kIU}$ of vitamin D, and 1,997.6 kIU of vitamin $\mathrm{E}$.

${ }^{2}$ Protein blend contained $30.2 \%$ canola meal solvent, $1.1 \%$ rumen-protected methionine (Smartamine; Adisseo, Antony, France), 11.2\% corn gluten meal, $45.2 \%$ rumen bypass protein (SoyPlus; Dairy Nutrition Plus, Ralston, IA), and $12.3 \%$ blood meal.

${ }^{3}$ Palmitic acid supplement contained 98\% C16:0 (Palmit 98; Global Agri-Trade, Long Beach, CA). independently for adiposity by 3 trained investigators on $\mathrm{d}-4,21,46$, and 63 (5-point BCS scale; Wildman et al., 1982) relative to the beginning of control or PALM treatments.

\section{Glucose Tolerance Tests}

Glucose tolerance tests (GTT) were performed on $\mathrm{d}-1,24$, and 49 relative to the start of treatment using previously described methods (Pires et al., 2007; Schoenberg et al., 2012). Briefly, a jugular catheter was inserted $24 \mathrm{~h}$ before the GTT, and patency was maintained by flushing with heparinized saline every 12 h. Following the removal of feed at $0800 \mathrm{~h}$, cows were intravenously infused with $300 \mathrm{mg}$ of glucose (dextrose, $50 \% \mathrm{wt} / \mathrm{vol}$ ) per kilogram of BW at $1000 \mathrm{~h}$. Glucose infusion occurred within $8 \pm 0.88 \mathrm{~min}$, and was followed by a $10-\mathrm{mL}$ saline flush. Blood samples $(10 \mathrm{~mL})$ were collected at $-10,0,10,20,30,40,60,90,120,150$, and 180 min relative to initiation of glucose infusion. Blood was processed as described above. Feed was provided immediately following the completion of the GTT.

\section{Sample Analyses}

Individually composited feed ingredients were analyzed for NDF with heat-stable $\alpha$-amylase and sodium sulfite (Van Soest et al., 1991), CP (AOAC International, 2000; method 990.03), and starch (Hall, 2009) by Cumberland Valley Analytical Services Inc. (Cumberland, MD).

Plasma samples were analyzed in duplicate for glucose, NEFA, insulin, triacylglycerol (TAG), and total cholesterol. Plasma concentrations of glucose, NEFA, TAG, and cholesterol were determined by enzymatic methods using commercial kits (Autokit Glucose, HR series NEFA-HR, L-Type TAG M, and Cholesterol E respectively; Wako Chemicals USA Inc., Richmond, VA). Plasma insulin concentrations were determined by ELISA (Mercodia Bovine Insulin ELISA; Mercodia AB, Uppsala, Sweden). Spectrophotometric measurements were conducted using a SpectraMax Plus 384 Microplate Reader (Molecular Devices, Sunnyvale, CA). Intra- and interassay coefficients of variation were 4.6 and 2.6, 3.7 and 3.7, 2.1 and 2.8, 3.1 and 6.1, and 3.0 and $7.0 \%$ for glucose, NEFA, TAG, total cholesterol, and insulin, respectively.

Individual milk samples were analyzed for fat, true protein, and lactose concentrations, as well as MUN using mid-infrared spectroscopy, and SCC was determined by flow cytometry (Dairy One, Hagerstown, MD; AOAC, 1990; method 972.160) within 1 wk of 
collection. For analysis of milk fatty acids composition, 4 individual milk samples were composited based on milk fat yield to represent the covariate period ( $\mathrm{d}-5$ and -4), wk 3 (d 20 and 21), and wk 7 (d 45 and 46) of the treatment period, and the completion of the posttreatment period (d 62 and 63, relative to the start of treatment). Samples were centrifuged at 17,800 $\times g$ for $30 \mathrm{~min}$ at $4^{\circ} \mathrm{C}$ and fat cakes were collected. Lipids from the fat cakes were extracted, methylated, and fatty acid composition determined by GLC, according to previously described methods (Lock et al., 2013). Short-chain FAME were corrected for mass discrepancy using the response factors described by (Ulberth and Schrammel, 1995). Individual fatty acid yields (g/d) were calculated using milk fat yield and fatty acid concentration to determine yield on a mass basis, using the molecular weight of each fatty acid while correcting for glycerol and other milk lipid classes (Piantoni et al., 2013).

\section{Calculations and Statistical Analysis}

Yields of ECM, 3.5\% FCM, and milk components were calculated using milk yield and components for each milking, summed for daily total, and averaged for each week of collection. Energy intake, energy balance, and feed efficiency were estimated using the Cornell Net Carbohydrate and Protein System (version 6.1; Tylutki et al., 2008) and calculated as follows: $\mathrm{NE}_{\mathrm{L}}$ intake $=\mathrm{kg}$ of DMI $\times$ Mcal per $\mathrm{kg}$ of apparent dietary $\mathrm{NE}_{\mathrm{L}}$; energy balance $=\mathrm{NE}_{\mathrm{L}}$ intake $-\left(\mathrm{NE}_{\mathrm{M}}+\mathrm{NE}_{\mathrm{L}}\right)$; and feed efficiency $=\mathrm{kg}$ of $\mathrm{ECM} / \mathrm{kg}$ of DMI. Plasma glucose, NEFA, and insulin concentrations were measured, and systemic insulin sensitivity estimated using the revised quantitative insulin sensitivity check index (RQUICKI; Holtenius and Holtenius, 2007), where RQUICKI $=1 /[\log ($ glucose $)+\log ($ insulin $)+\log$ $(\mathrm{NEFA})]$, and glucose = basal glucose $(\mathrm{mg} / \mathrm{dL})$, insulin $=$ basal insulin $(\mu \mathrm{U} / \mathrm{mL})$, and NEFA = basal NEFA (mmol/L), such that lowered RQUICKI values indicate a reduction in insulin sensitivity, and higher values indicate elevations in insulin sensitivity. The area under the curve (AUC) for glucose and NEFA during GTT was calculated using the trapezoidal method as previously described by Pires et al. (2007).

All data were analyzed as repeated measures over time using the MIXED model procedure of SAS (version 9.3; SAS Institute Inc., Cary, NC) according to the following model:

$$
\begin{gathered}
\mathrm{Y}_{\mathrm{ijk}}=\mu+\mathrm{C}_{\mathrm{i}}+\mathrm{P}_{\mathrm{j}}+\mathrm{T}_{\mathrm{k}(\mathrm{i})}+\left(\mathrm{P}_{\mathrm{j}} \times \mathrm{T}_{\mathrm{k}}\right)+\mathrm{pMY} \\
+\left(\mathrm{pMy} \times \mathrm{T}_{\mathrm{k}}\right)+\mathrm{e}_{\mathrm{ijk}},
\end{gathered}
$$

where $Y_{i j k}=$ dependent variable, $\mu=$ overall mean, $C_{i}=$ random effect of cow nested within treatment $(\mathrm{i}=1$ to 20), $P_{j}=$ fixed effect of sampling time ( $\mathrm{j}=1$ to 3,0 to 63 , or 0 to 180 for week, day, and minute, respectively), $\mathrm{T}_{\mathrm{k}(\mathrm{i})}=$ fixed effect of treatment $(\mathrm{k}=1$ to 2$), \mathrm{P}_{\mathrm{j}} \times \mathrm{T}_{\mathrm{k}}$ $=$ interaction between sampling week and treatment, $\mathrm{pMy}=$ preliminary milk yield used as a covariate, $\mathrm{pMy}$ $\times \mathrm{T}_{\mathrm{k}}=$ interaction between treatment and preliminary milk yield, and $e_{i j k}=$ residual error. Interactions were evaluated but removed from the statistical model when not significant $(P>0.10)$. For data that were evaluated continuously, effect of sampling week was replaced with the effect of sampling day. Normality of the residuals was checked with normal probability and box plots and homogeneity of variances with plots of residual versus predicted values. When necessary, data were log-transformed for analysis. The method of KenwardRogers was used for calculation of denominator degrees of freedom. The SLICE option of SAS was used to compare treatment differences at individual time points. To reduce risk of type I error for repeated measures analysis, the significance level was decreased to $P \leq$ 0.05 , and trends toward significance were considered at $0.05<P \leq 0.10$. Studentized residual values $>3.0$ or $<-3.0$ were considered outliers and removed from the analysis (typically 1 per response variable). All results are expressed as least squares means and their standard errors, unless stated otherwise.

\section{RESULTS}

The C16:0-enriched fat supplement was included at $3.9 \%$ of ration DM, with soyhulls substituted in the control treatment (Table 1). Content of DM, NDF, $\mathrm{CP}$, and starch, were comparable between treatments. Ether extract and $\mathrm{NE}_{\mathrm{L}}$ were higher in PALM, relative to control. All cows had similar milk yield, milk fatty acid yields and concentration, ECM, 3.5\% FCM, DMI, energy intake, BW, and BCS during the covariate period (Supplemental Tables S1 and S2; http://dx.doi. org/10.3168/jds.2016-11295).

\section{Production Responses}

When analyzed continuously, DMI was not modified before or after treatment (Figure 1). However, PALM increased milk yield but was dependent upon time (Figure $1 ; P<0.01)$. Specifically, PALM increased milk yield by d 15 (26.6 vs. $32.0 \mathrm{~kg} / \mathrm{d}, P<0.05)$, a response that was observed repeatedly during treatment (e.g., 26.5 vs. 32.0 and 24.4 vs. $29.0 \mathrm{~kg} / \mathrm{d}$ for d 18 and 49 , respectively; $P<0.05$ ). Posttreatment, milk yield converged for control and PALM. Coinciding with the 

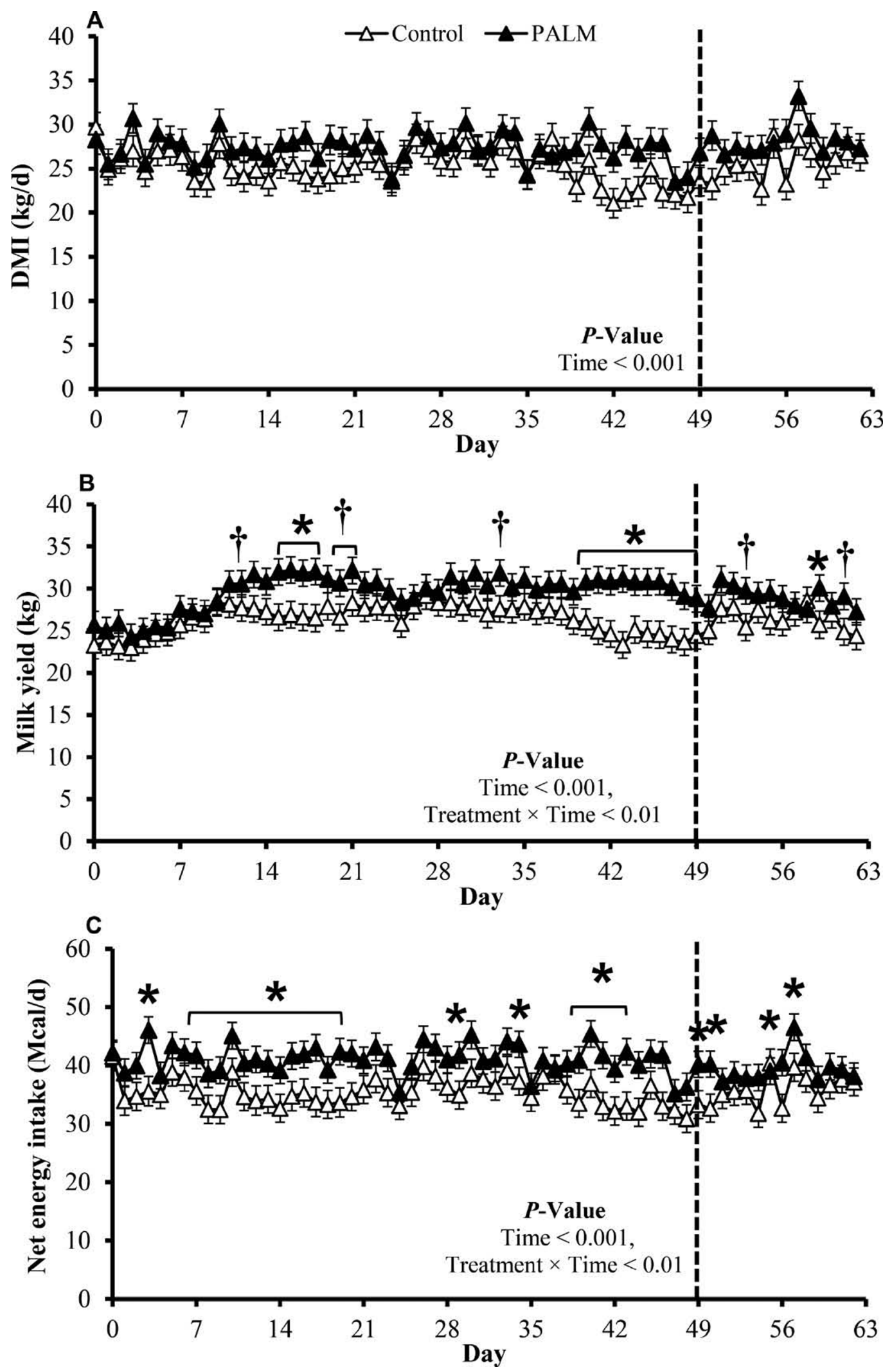

Figure 1. Palmitic acid supplementation increases milk yield and net energy intake. Continuous evaluation of (A) DMI (kg/d), (B) milk yield $(\mathrm{kg} / \mathrm{d})$, and $(\mathrm{C})$ energy intake (Mcal/d) in mid-lactation cows fed C16:0 at 3.9\% of diet DM (PALM) or control diets. Data are LSM and SE. $* P<0.05 ; \nmid P<0.10$ compared with control. 
start of treatment, energy intake was greater in PALMfed cows (treatment $\times$ time, $P<0.01$; Figure 1 ) and was elevated less frequently posttreatment.

Milk production and composition were further evaluated by pooling samples and data at wk 3 and 7 (Table 2 ). Similar to the continuous evaluation of milk yield, PALM-fed cows produced $19 \%$ more milk by wk 7 ( $P$ $<0.05$ ); however, this response was not observed posttreatment. The PALM treatment increased milk fat yield by 18 and $23 \%(P<0.01)$ and ECM by 13 and $19 \%(P<0.05)$ at wk 3 and 7 , respectively, and these responses remained by wk 2 posttreatment $(P=0.05)$. Supplementing PALM tended to increase milk protein yield by wk $7(P<0.05)$, an effect that remained during the posttreatment evaluation $(P=0.03)$. The PALM treatment did not modify milk fat concentration or MUN. Although we detected a tendency for increased DMI $(P=0.09)$, we did observe an increase in energy intake (18\% average) in cows supplemented with PALM $(P<0.01)$, results that are comparable to our continuous evaluation. In contrast, feed efficiency was not modified before or after PALM treatment. We did not observe any differences in BCS, BW, or energy balance for PALM versus control treatments.

\section{Milk Fatty Acid Yields and Concentrations}

Relative to control, PALM increased milk C16:0 yield by 52 and $50 \%$ by wk 3 and 7 , respectively $(P<$ 0.001; Table 3). Similar observations were observed for milk $\mathrm{C} 16: 1$. In contrast, the yield of $\mathrm{C} 16: 0$ in milk was similar for both groups 2 wk following the termination of treatments. Although the total yield of preformed fatty acids in milk remained unchanged during the treatment period, milk SFA yield increased by 29 and $24 \%$ in PALM-fed cows at wk 3 and 7 , respectively $(P<0.001)$. Total yields of fatty acids synthesized de novo, preformed fatty acids, as well as MUFA and PUFA in milk remained unchanged during the treatment period. Interestingly, we observed 24 and $22 \%$ increases in yields of de novo and preformed fatty acids in PALM cows posttreatment $(P \leq 0.01)$. For example, posttreatment increases in milk yields of C6:0, C8:0, C10:0, C12:0, C14:0, 18:0, cis-9 C18:1, and cis-9, cis-12 C18:2 ranged from 19 to $36 \%(P<0.05)$ in PALM versus control cows.

In a similar manner, PALM modified the concentrations of milk fatty acids (Table 4). Relative to control, PALM increased milk C16:0 concentration by 26 and $21 \%$ at wk 3 and 7 , respectively $(P<0.001)$. Likewise, SFA concentration increased by 4.1 and $3.8 \%$ in PALM cows at wk 3 and 7 , respectively $(P<0.01)$. In contrast, the concentrations of UFA were lower in PALM cows. The concentrations of most de novo synthesized fatty acids were 18 and $12 \%$ lower in PALM cows by wk 3 and 7 , respectively $(P<0.01)$. For example, PALM lowered the concentrations of C6:0, C8:0, C10:0, C12:0, and C14:0 fatty acids in milk, which ranged from 11 to $25 \%$ at wk $3(P<0.05)$. In contrast to changes in milk fatty acids yields, we did not detect any treatment differences in the concentrations of milk fatty acids, including C16:0, during the posttreatment period.

\section{Plasma Metabolite Responses}

The PALM treatment increased basal plasma NEFA by 48,93 , and $60 \%$ on d 4,6 , and 8 of treatment, respectively (interaction $P<0.05$; Figure 2); however, coinciding with enhanced milk production, PALM did not affect plasma NEFA following d 8. Consistent with the advancement of lactation, the level of NEFA in plasma declined with time in all cows $(P<0.01)$. Unexpectedly, we observed a higher concentration of insulin in control-fed cows at the onset of treatment (interaction $P<0.05$; Figure 2 ). We also measured a gradual rise in circulating insulin with the progression of lactation $(P<0.05)$. We did not detect any changes in circulating glucose with treatment (Figure 2). In parallel with our observed plasma NEFA response, PALM cows displayed lower RQUICKI values at $\mathrm{d} 6$ and 8 (38 and 35\%, respectively; $P<0.01$; Figure 2), reflecting an acute decrease in estimated insulin sensitivity in PALM-fed cows. Although PALM increased circulating NEFA during the short term, PALM did not modify circulating TAG (Figure 3). Conversely, total cholesterol concentration in plasma was 50 and $51 \%$ greater in PALM cows by wk 3 and 7 , respectively $(P$ $<0.01$; Figure 3).

Supplementing cows with PALM did not modify circulating glucose following intravenous glucose infusion during the duration of treatment (Figure 4). Furthermore, PALM did not modify glucose AUC during the GTT (Supplemental Table S3; http://dx.doi. org/10.3168/jds.2016-11295). The magnitude of plasma NEFA disappearance following a glucose challenge progressively decreased with duration of PALM treatment (Figure 4). Thus, PALM-fed cows had a tendency for reduced NEFA disappearance 60 min after glucose infusion (nadir of curve) on d 24 of treatment $(P<0.10)$, a response that was significantly greater by d 49 (interaction $P<0.001$ ). Additionally, PALM increased AUC for NEFA during the GTT (Supplemental Table S3).

\section{DISCUSSION}

Previous research studies that evaluated the effects of C16:0-enriched supplements on milk production have included short-term study lengths, varying dietary lev- 
MATHEWS ET AL.

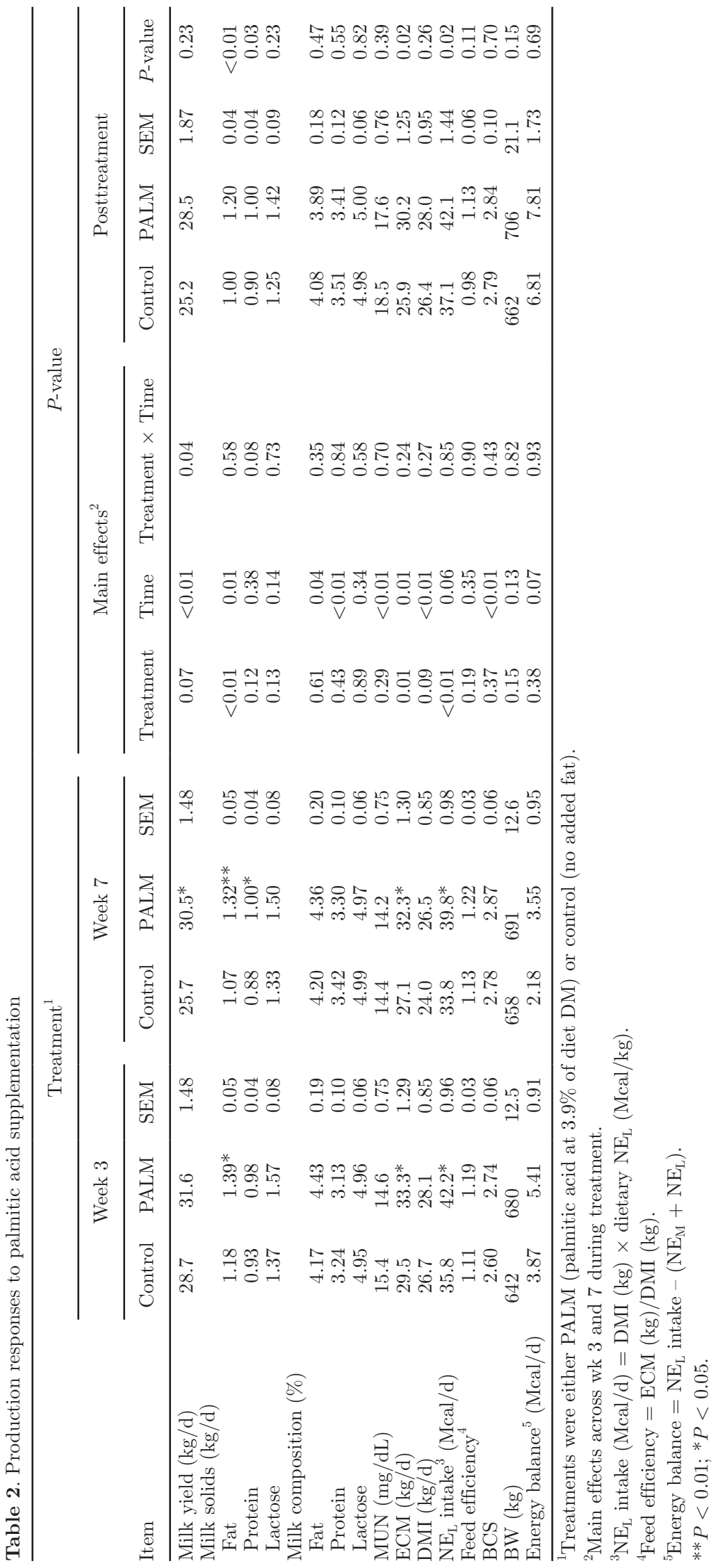




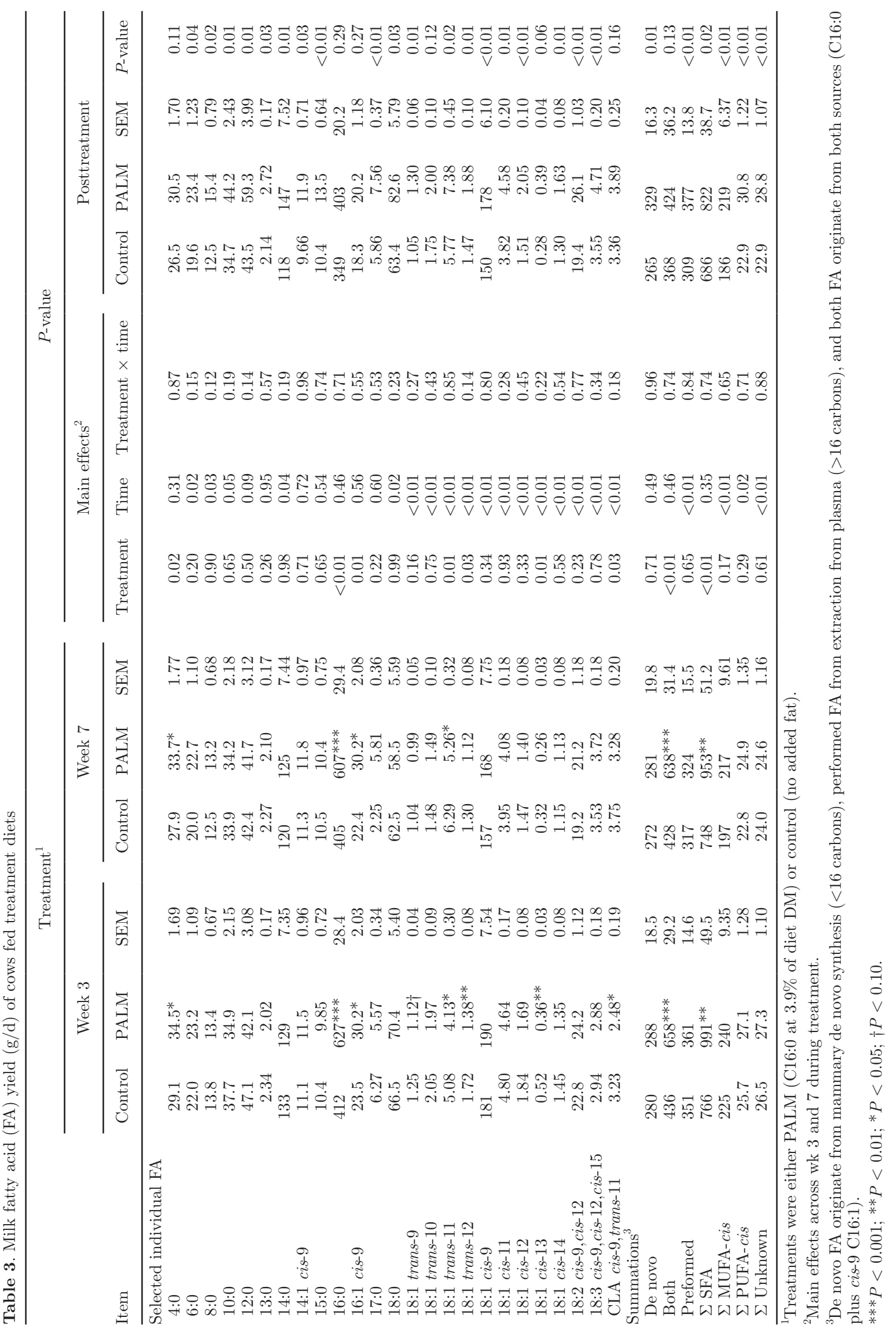




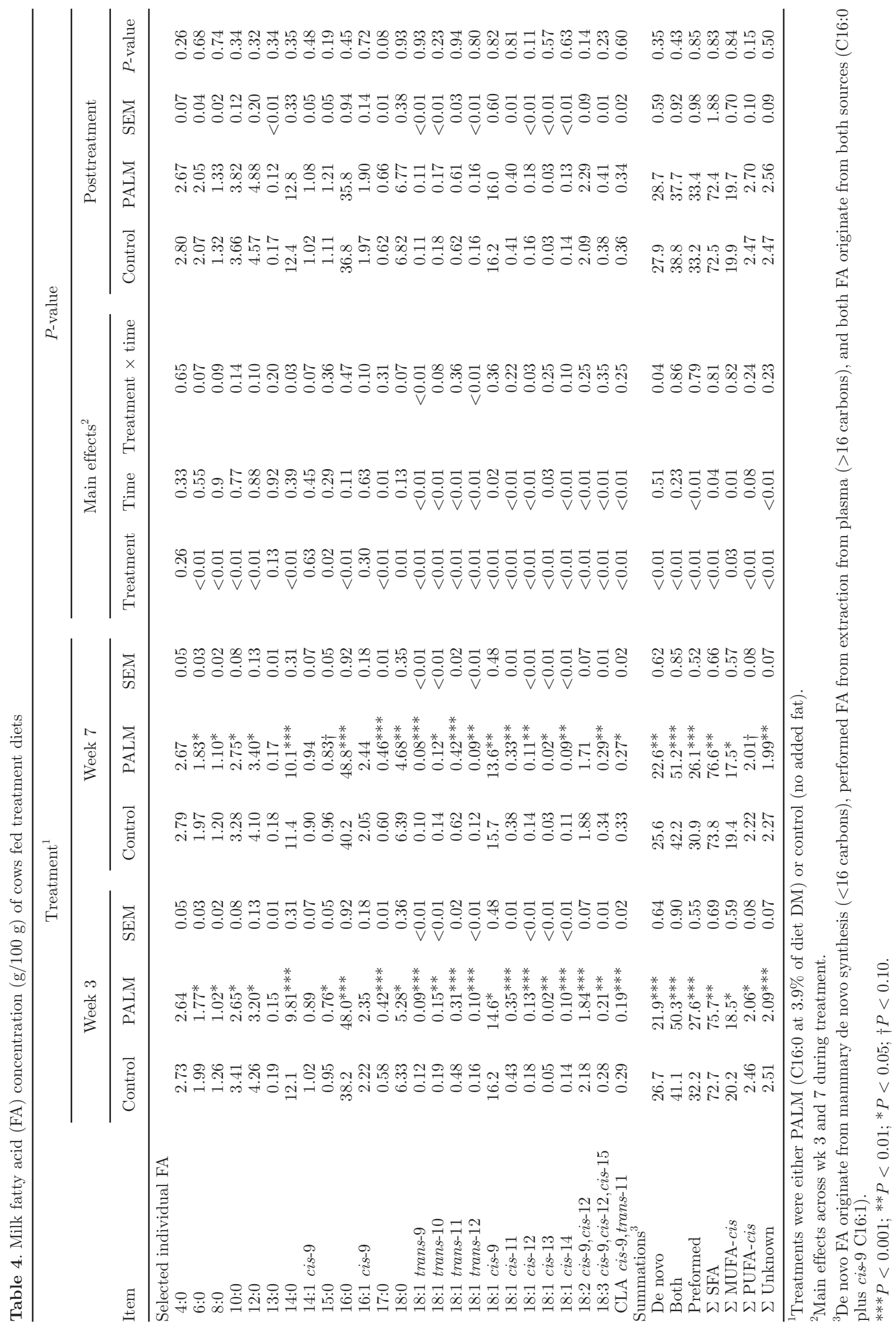


els of C16:0, and brief sampling windows near the end of treatment (Loften et al., 2014) with variable production responses. Furthermore, the effects of prolonged C16:0 supplementation for $7 \mathrm{wk}$ or the effects following treatment removal on milk production and composition have not been investigated. Considering that circulating lipid availability is linked with the development of insulin resistance and nutrient partitioning during early lactation, and that increasing circulating SFA can antagonize insulin action, we chose to further explore the effects of dietary C16:0 on systemic glucose tolerance and lipolytic response following a series of glucose challenges. Because beneficial changes in milk production outcomes are inconsistent and Piantoni et al. (2013) did not observe a change in glucose tolerance when C16:0 was fed at $2 \%$ of diet DM for $3 \mathrm{wk}$, we chose to use a high dietary feeding level of C16:0
(3.9\% of diet DM) relative to industry applications for a longer period of time $(7 \mathrm{wk})$. Although our experimental design differed, our feeding level of palmitic acid was comparable to previous work by Steele (1969) and Mosley et al. (2007). We also evaluated changes in milk production and composition following the 2 wk removal of supplemental C16:0. Our sample size does represent a potential study limitation; however, our repeated measures analysis revealed many significant production and metabolic effects that were only observed during the high dietary inclusion of palmitic acid.

Although we did not record significant improvements in milk yield with C16:0 until d 15 of PALM treatment, daily milk yields averaged 26.3 and $29.7 \mathrm{~kg}$ (control vs. PALM, respectively) over the duration of the $49-\mathrm{d}$ treatment. Furthermore, maximum gains of $4.8 \mathrm{~kg} / \mathrm{d}$ were observed in cows consuming supplemental C16:0

\section{A-Control - - PALM}

A

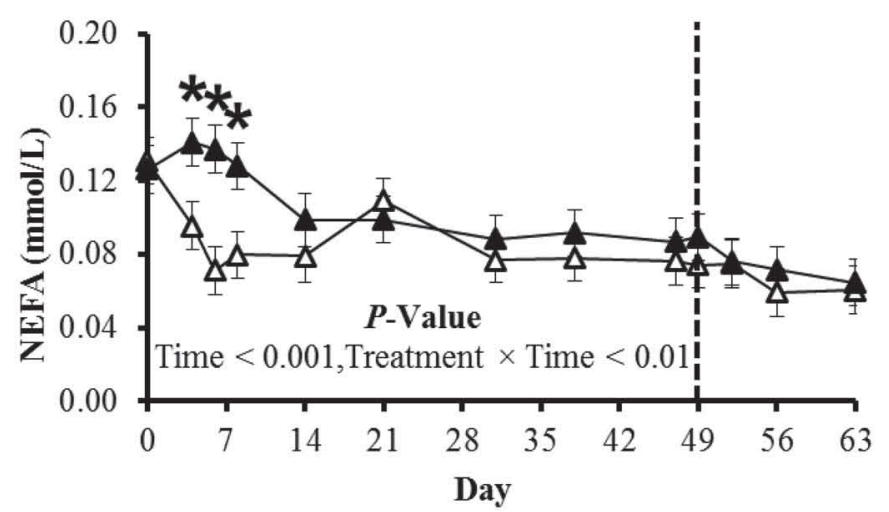

C

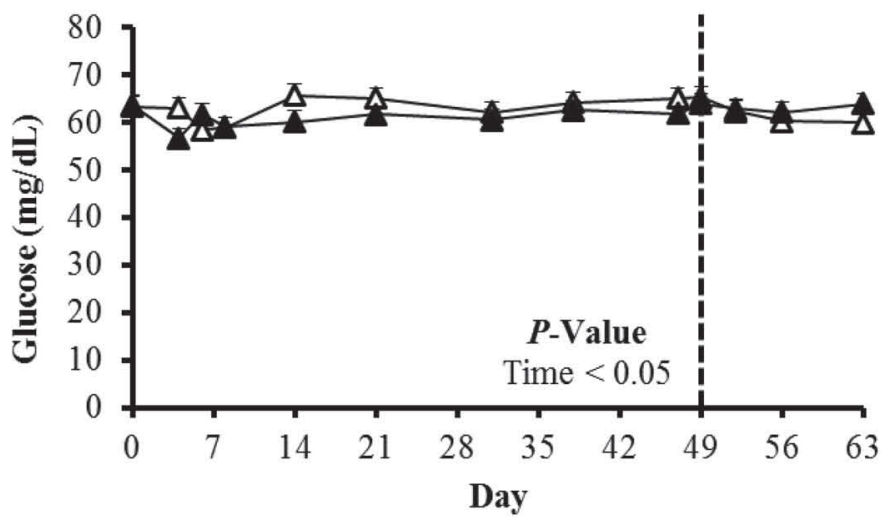

B

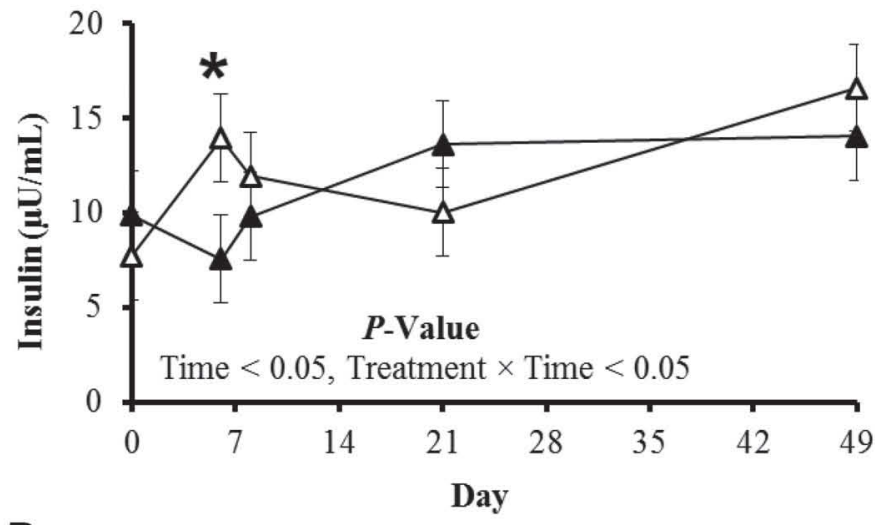

D

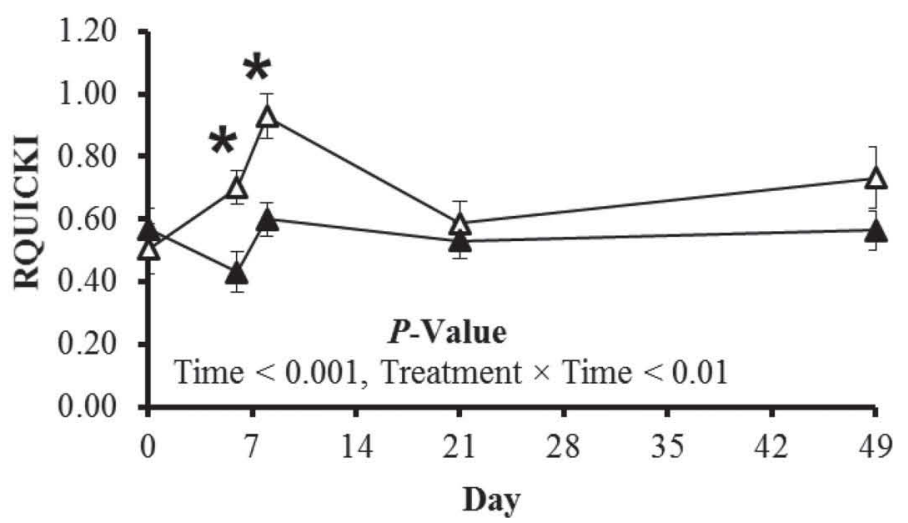

Figure 2. Palmitic acid supplementation acutely increases circulating nonesterified fatty acids (NEFA) and decreases estimated insulin sensitivity. Plasma concentrations of (A) NEFA, (B) insulin, and (C) glucose of mid-lactation dairy cattle fed control or C16:0 at 3.9\% of diet DM (PALM) diets. (D) Estimated insulin sensitivity as measured by the revised quantitative insulin sensitivity check (RQUICKI), where RQUICKI was calculated as follows: $1 /[\log ($ glucose $)+\log ($ insulin $)+\log (\mathrm{NEFA})]$. Lower RQUICKI values are indicative of reduced insulin sensitivity. Data are LSM and SE. ${ }^{*} P<0.05$ compared with control. 


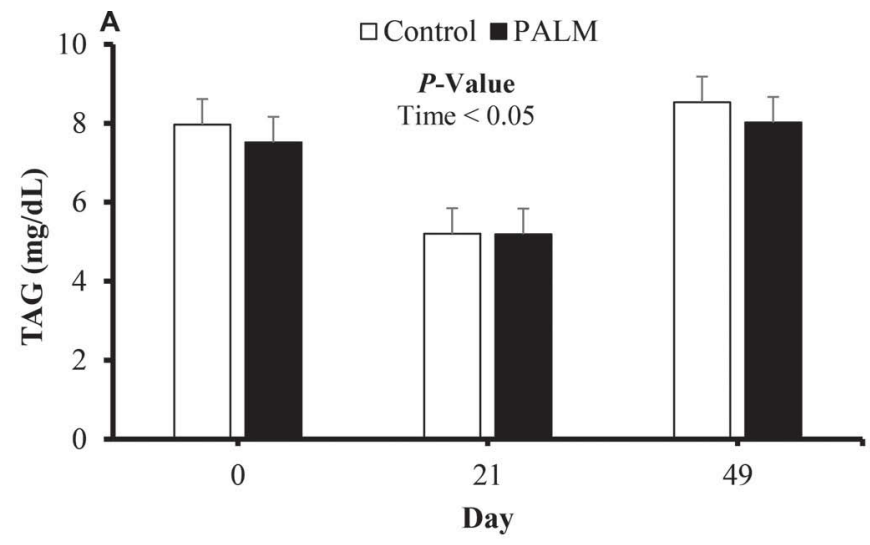

B

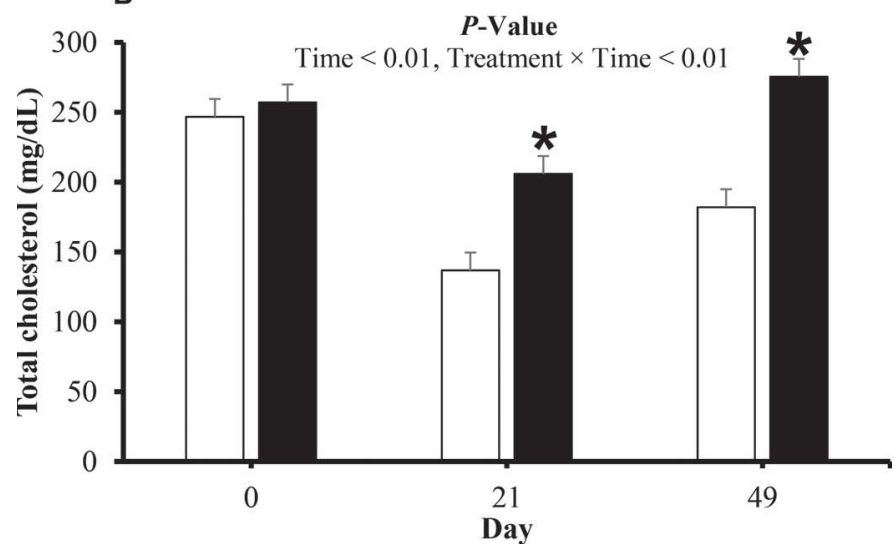

Figure 3. Feeding cows C16:0 increases circulating cholesterol without modifying circulating triacylglycerol (TAG). Plasma concentrations of (A) TAG and (B) total cholesterol in mid-lactation cows fed control or C16:0 at 3.9\% of diet DM (PALM) diets. Data are LSM and SE. ${ }^{*} P<0.05$ compared with control.

at $3.9 \%$ of diet DM $(1,013 \mathrm{~g} / \mathrm{d})$ by wk 7 . In comparison, Mosley et al. (2007) observed an increase of $3.3 \mathrm{~kg} / \mathrm{d}$ of milk produced by cows consuming diet containing alfalfa silage and $1,000 \mathrm{~g} / \mathrm{d}$ of fatty acids of palm oil containing approximately $808 \mathrm{~g} / \mathrm{d}$ of palmitic acid for 16 $\mathrm{d}$, when compared with a nonsupplemented control diet containing lower $\mathrm{NE}_{\mathrm{L}}$. Likewise, Steele (1969) reported increases in milk yields of $1 \mathrm{~kg} / \mathrm{d}$ in cows supplemented with $\mathrm{C} 16: 0(\sim 85 \% \mathrm{C} 16: 0)$ at $4.25 \%$ of diet DM for $35 \mathrm{~d}$ relative to an isocaloric diet with starch replacement. In contrast, Rico et al. (2014b) did not observe a change in milk yield when mid-lactations cows were fed isoenergetic diets containing high-purity fatty acid supplements containing palmitic acid or stearic acid at $2 \%$ of diet DM. We cautiously recognize that our observed gains in milk yield may not be specific for palmitic acid feeding, but rather are an outcome of increased energy intake. Future research will need to evaluate the effects of long-term palmitic acid feeding on production in comparison with an isoenergetic control diet.
Comparable to Piantoni et al. (2013), we did not detect a significant change in DMI. In contrast to other studies that compared diets supplemented with C16:0 with nonsupplemented controls (Steele, 1969; Mosley et al., 2007; Piantoni et al., 2013), PALM did not increase milk fat, protein, or lactose concentrations. However, PALM supplementation did increase milk fat yield $(+210$ and $+250 \mathrm{~g} / \mathrm{d}$ by wk 3 and 7 , respectively). At comparable C16:0 treatment levels, Mosley et al. (2007) and Steele (1969) reported gains in milk fat yields of 302 and $115 \mathrm{~g} / \mathrm{d}$, respectively. Our results also demonstrate that improvements in milk fat yield with PALM treatment are sustained for the duration of a 7 -wk treatment period. Comparable to others (Steele, 1969; Mosley et al., 2007; Piantoni et al., 2013), we did not observe changes in milk protein yield by wk 3 ; however, milk protein yield was greater in PALM fed cows by wh 7 $(+120 \mathrm{~g} / \mathrm{d})$. Because we observed an increase in energy intake due to increased dietary C16:0, AA utilization may have been partitioned away from nonmammary tissues and toward milk protein synthesis. Similar to others (Piantoni et al., 2013; Rico et al., 2014b), we observed an increase in ECM by wk 3 and 7 (12 and $19 \%$, respectively). Because BCS and BW were not significantly different between treatments, we considered increased energy intake to possibly have been diverted toward milk and milk component production and away from adipose or skeletal muscle tissue accretion. Two weeks following the removal of PALM, milk yield converged between the treatment groups; however, ECM remained elevated in parallel with a sustained elevation in milk fat and protein yields. The posttreatment increase in ECM occurred in parallel with a continued increase in energy intake observed in cows previously fed PALM.

Our observed changes in milk fatty acid yields during PALM are consistent with related studies (Mosley et al., 2007; Lock et al., 2013; Piantoni et al., 2013). Treatment with C16:0 did not affect de novo synthesized or preformed fatty acid yields in milk during treatment; however, PALM did increase SFA yields due to an increase in C16:0 incorporation. The absence of an increase in de novo fatty acid synthesis with enhanced milk yield may be due to the allosteric inhibition of acetyl-CoA carboxylase (Storry et al., 1973; Wright et al., 2002). As opposed to treatment, the removal of supplemental C16:0 for 2 wk increased de novo milk fat synthesis. Additionally, the removal of supplemental C16:0 enhanced the incorporation of preformed fatty acids into milk fat. The observed increase in de novo and preformed fatty acids in milk after treatment may reflect the sustained elevation in energy intake, albeit elevated dietary energy was independent of C16:0. The cow's ability to remodel milk fatty acid composition 
to maintain elevated ECM and milk fat yield for $2 \mathrm{wk}$ beyond C16:0 removal is intriguing, and the extent of this preservation should be further investigated.

Saturated fatty acid feeding has been reported to increase circulating NEFA in dairy cows (Piantoni et al., 2013; Rico et al., 2014b). In our study, the basal concentrations of NEFA in plasma were elevated in PALM-fed cows exclusively during the initial 2 wk of treatment, immediately before enhanced daily yields of milk and milk fat. The ability of supplemental SFA to increase NEFA is well documented (Grummer, 1991). For instance, Rico et al. (2014b) observed elevated plasma NEFA in mid-lactation cows fed C16:0, relative to C18:0 feeding (Rico et al., 2014b). The mechanisms responsible for these elevations in NEFA observed with C16:0 feeding have not been delineated. The rise in circulating NEFA may be caused by the enhanced intake of dietary C16:0; however, we recognize that fatty
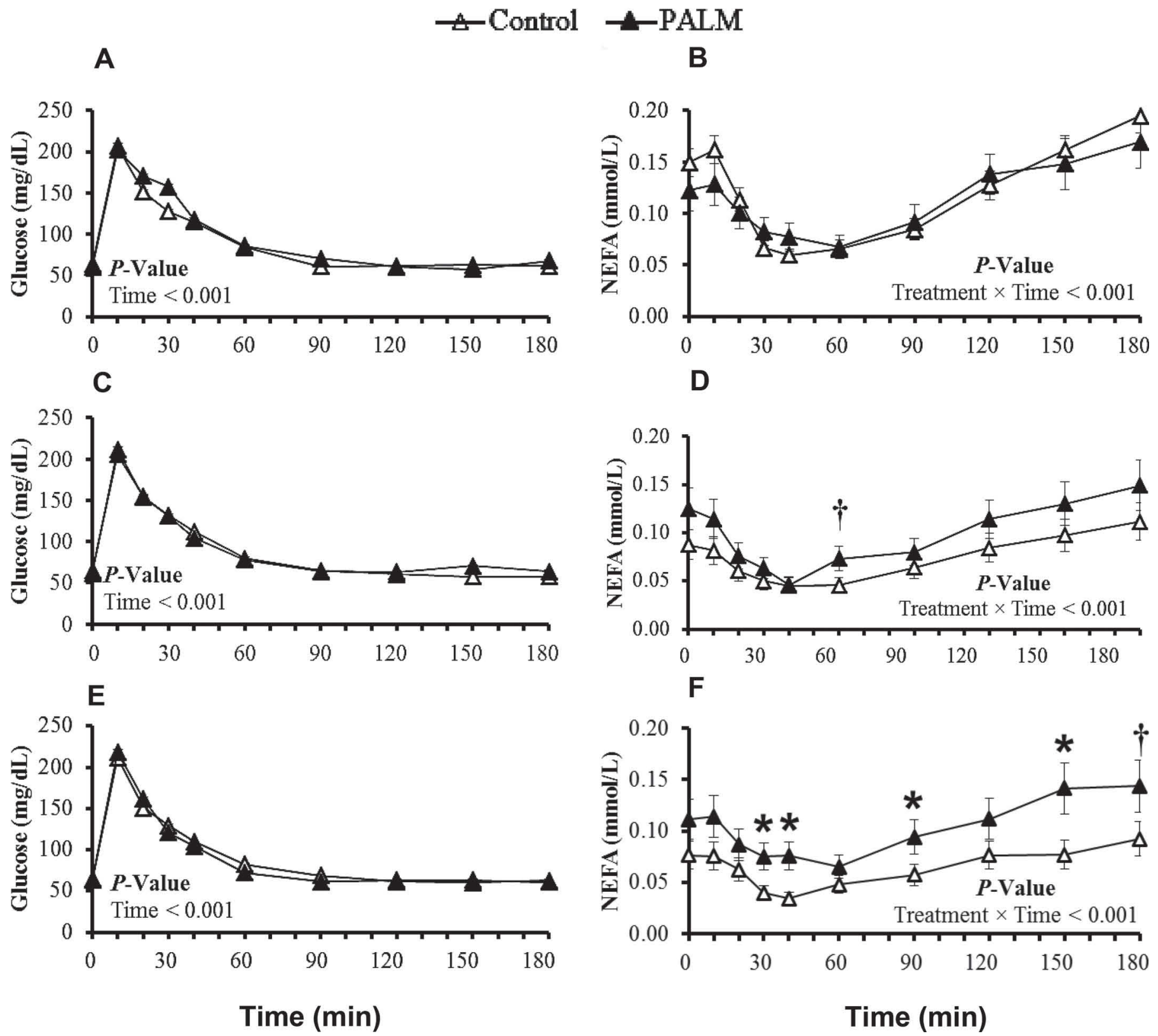

Figure 4. Palmitic acid feeding does not modify glucose tolerance but reduces glucose-stimulated nonesterified fatty acid (NEFA) disappearance. Relative to the initiation of treatment, plasma concentrations of (A, C, and E) glucose and (B, D, and F) NEFA in control and C16:0 at $3.9 \%$ of diet DM (PALM) cows challenged with intravenous glucose (300 $\mathrm{mg} / \mathrm{kg}$ of BW) on d $-1,24$, and 49 , respectively. Data are LSM and SE. ${ }^{*} P<0.05 ; \dagger P<0.10$ compared with control 
acids greater than $\mathrm{C} 12$ are converted to their CoA derivatives and re-esterified as TAG once absorbed (Bach and Babayan, 1982). The TAG are subsequently packaged into chylomicrons and readily hydrolyzed by lipoprotein lipase in tissues (Christie et al., 1986), an action that contributes to circulating NEFA supply in ruminants (Bergman et al., 1971; Pethick and Dunshea, 1993) that may depend on tissue-specific lipase activity (Bickerton et al., 2007). Considering this evidence, the elevations in NEFA observed with PALM may be from dietary origin. Alternatively, an increase in circulating NEFA may reflect greater adipose tissue lipolysis in cows fed C16:0, as suggested by Piantoni et al. (2013); however, we did not observe a change in BCS in PALM-fed cows experiencing positive energy balance. Although not evaluated by Piantoni et al. (2013), we observed an acute decrease in plasma insulin concentrations within the first week of C16:0 feeding; therefore, the antilipolytic action of insulin may have been diminished to support short-term NEFA mobilization. In support, we observed a gradual increase in circulating insulin concurrent with a decline in plasma NEFA as cows progressed toward late lactation. Similar to Piantoni et al. (2013), we did not observe a change in plasma TAG in cows fed C16:0; however, we did observe a $51 \%$ increase in circulating total cholesterol by wk 7. The abomasal infusion of fatty acids of palm oil or the feeding of C16:0-incorporated diets has also been shown to increase the concentration of cholesterol in plasma (Bremmer et al., 1998; van Knegsel et al., 2007; Andersen et al., 2008). Our observed rise in circulating cholesterol with PALM may be due to enhanced formation and lower turnover of low-density lipoproteins, as suggested by Fernandez and West (2005). Because we chose to evaluate the metabolic response to PALM feeding during the basal state, future work will need to assess whether similar metabolic responses occur diurnally in response to palmitic acid feeding.

The ability of SFA to antagonize insulin action and promote glucose intolerance is well documented in monogastrics (Summers, 2006; Funaki, 2009); however, the ability of SFA to modify insulin action in ruminants is uncertain. In our evaluation of 7-wk C16:0 supplementation, we did not observe a change in estimated insulin sensitivity or systemic glucose tolerance in PALM-fed cows at wk 3 or 7. Comparably, Piantoni et al. (2013) did not observe a change in systemic insulin sensitivity in mid-lactation cows fed C16:0 at $2 \%$ of diet DM following 3 wk of supplementation, as measured using a GTT as well as an insulin tolerance test. Induction of hyperlipidemia by abomasally infusing tallow or restricting access to feed impairs glucose clearance during a GTT in nonlactating, nonpregnant Holstein cows (Pires et al., 2007); however, augmented NEFA availability during early lactation does not diminish glucose clearance (Saed Samii et al., 2015; Mann et al., 2016). In lactating cows, the inability of SFA to suppress glucose removal following a challenge is likely due to enhanced glucose uptake by the mammary gland (Kronfeld, 1982; Debras et al., 1989), a possible explanation for the similar glucose tolerance measurements observed in our study. Prior to the increase in milk yield, we did observe a decrease in estimated insulin sensitivity exclusively at wk 1 of supplementation, a response that disappeared as the availability of basal plasma insulin increased and plasma NEFA declined with the progression of lactation. The evaluation of RQUICKI across time (i.e., stages of lactation) should be evaluated carefully because this index of insulin sensitivity does not correspond to direct measurements of insulin sensitivity (GTT or insulin tolerance testing; Saed Samii et al., 2015; Mann et al., 2016), and does not account for NEFA that may be derived from dietary origin. Because the development of fatty acidinduced insulin resistance in lactating dairy cows may be localized to adipose tissue (Zachut et al., 2013), we evaluated changes in circulating NEFA during a series of GTT measurements and observed a progressive decline in glucose-stimulated NEFA disappearance in PALM-fed cows. Because insulin can suppress adipose tissue lipolysis, C16:0-induced adipose tissue insulin resistance may have lessened the antilipolytic effect of the glucose challenges. The ability of C16:0 to antagonize protein kinase B-dependent insulin signaling in adipose tissue may be mediated by lipid mediators, such as ceramide, biomarkers for insulin resistance in insulin resistant humans (Haus et al., 2009) and dairy cattle (Rico et al., 2015). The possible role of C16:0 to mediate adipose tissue insulin resistance and support glucose partitioning to the mammary gland requires further consideration.

\section{CONCLUSIONS}

Our results demonstrate that long-term feeding of mid-lactation cows with C16:0 enhances the yield of milk and milk components without suppressing DMI, relative to no added fat supplementation. Gains in milk fat yield during C16:0 supplementation were exclusively due to an increase in C16:0 and C16:1 incorporation into milk fat. The evaluation of metabolic health status revealed acute elevations in basal circulating NEFA and estimated insulin resistance that preceded beneficial improvements in milk production. Although glucose tolerance was not modified with C16:0 feeding, the intake of C16:0 for an extended duration enhanced circulating cholesterol and lowered glucose-stimulated NEFA disappearance. Intriguingly, beneficial milk 
production responses were sustained for 2 wk following the removal of C16:0 from the diet. Further studies are required to investigate the effects of $\mathrm{C} 16: 0$ on localized adipose tissue insulin sensitivity and nutrient partitioning toward the mammary gland.

\section{ACKNOWLEDGMENTS}

This work was supported by Hatch Project WVA00661 and the Davis College of Agriculture, Natural Resources and Design (Morgantown, WV). The authors thank Jurgen Godau (Global Agri-Trade, Long Beach, CA) for supplying the Palmit 98 supplement. We also gratefully acknowledge Sina Saed Samii, Yu Zang, Rachel Cokeley, Loretta Aromeh, and the farm staff from West Virginia University, and Courtney Preseault from Michigan State University for their technical assistance. This is Scientific Article No. 3280 of the West Virginia Agricultural and Forestry Experiment Station, Morgantown.

\section{REFERENCES}

Andersen, J. B., C. Ridder, and T. Larsen. 2008. Priming the cow for mobilization in the periparturient period: Effects of supplementing the dry cow with saturated fat or linseed. J. Dairy Sci. 91:1029-1043.

AOAC. 1990. Official Methods of Analysis. 15th ed. Association of Official Analytical Chemists, Arlington, VA.

AOAC International. 2000. Official Methods of Analysis. 17th ed. AOAC International, Gaithersburg, MD.

Bach, A. C., and V. K. Babayan. 1982. Medium-chain triglycerides: An update. Am. J. Clin. Nutr. 36:950-962.

Bell, A. W. 1995. Regulation of organic nutrient metabolism during transition from late pregnancy to early lactation. J. Anim. Sci. $73: 2804-2819$.

Bell, A. W., and D. E. Bauman. 1997. Adaptations of glucose metabolism during pregnancy and lactation. J. Mammary Gland Biol. Neoplasia 2:265-278.

Bergman, E. N., R. J. Havel, B. M. Wolfe, and T. Bohmer. 1971. Quantitative studies of the metabolism of chylomicron triglycerides and cholesterol by liver and extra hepatic tissues of sheep and dogs. J. Clin. Invest. 50:1831-1839.

Bickerton, A. S. T., R. Roberts, B. A. Fielding, L. Hodson, E. E. Blaak, A. J. M. Wagenmakers, M. Gilbert, F. Karpe, and K. N. Frayn. 2007. Prefertional uptake of dietary fatty acids in adipose tissue and muscle in the postprandial period. Diabetes 56:168-176.

Bremmer, D. R., L. D. Ruppert, J. H. Clark, and J. K. Drackley. 1998. Effects of chain length and unsaturation of fatty acid mixtures infused into the abomasum of lactating dairy cows. J. Dairy Sci. $81: 176-188$.

Christie, W. W., R. C. Noble, and R. A. Clegg. 1986. The hydrolysis of very low density lipoproteins and chylomicrons of intestinal origin by lipoprotein lipase in ruminants. Lipids 21:252-253.

Contreras, G. A., N. J. O'boyle, T. H. Herdt, and L. M. Sordillo. 2010. Lipomobilization in periparturient dairy cows influences the composition of plasma nonesterified fatty acids and leukocyte phospholipid fatty acids. J. Dairy Sci. 93:2508-2516.

De Koster, J. D., and G. Opsomer. 2013. Insulin resistance in dairy cows. Vet. Clin. North Am. Food Anim. Pract. 29:299-322.

Debras, E., J. Grizard, E. Aina, S. Tesseraud, C. Champredon, and M. Arnal. 1989. Insulin sensitivity and responsiveness during lactation and dry period in goats. Am. J. Physiol. 256:E295-302.
Fernandez, M. L., and K. West. 2005. Mechanisms by which dietary fatty acids modulate plasma lipids. J. Nutr. 135:2075-2078.

Funaki, M. 2009. Saturated fatty acids and insulin resistance. J. Med. Invest. 56:88-92.

Grummer, R. R. 1991. Effect of feed on the composition of milk fat. J. Dairy Sci. 74:3244-3257.

Hall, M. B. 2009. Determination of starch, including maltooligosaccharides, in animal feeds: Comparison of methods and a method recommended for AOAC collaborative study. J. AOAC Int. 92:42-49.

Haus, J. M., S. R. Kashyap, T. Kasumov, R. Zhang, K. R. Kelly, R. A. Defronzo, and J. P. Kirwan. 2009. Plasma ceramides are elevated in obese subjects with type 2 diabetes and correlate with the severity of insulin resistance. Diabetes 58:337-343.

Holtenius, P., and K. Holtenius. 2007. A model to estimate insulin sensitivity in dairy cows. Acta Vet. Scand. 49:29.

Kronfeld, D. S. 1982. Major metabolic determinants of milk volume, mammary efficiency, and spontaneous ketosis in dairy cows. J. Dairy Sci. 65:2204-2212.

Lock, A. L., C. L. Preseault, J. E. Rico, K. E. Deland, and M. S. Allen. 2013. Feeding a c16:0-enriched fat supplement increased the yield of milk fat and improved conversion of feed to milk. J. Dairy Sci. 96:6650-6659.

Loften, J. R., J. G. Linn, J. K. Drackley, T. C. Jenkins, C. G. Soderholm, and A. F. Kertz. 2014. Invited review: Palmitic and stearic acid metabolism in lactating dairy cows. J. Dairy Sci. 97:46614674 .

Mann, S., F. L. Yepes, M. Duplessis, J. J. Wakshlag, T. R. Overton, B. P. Cummings, and D. V. Nydam. 2016. Dry period plane of energy: Effects on glucose tolerance in transition dairy cows. J. Dairy Sci. 99:701-717.

McNamara, J. P., and J. K. Hillers. 1986. Adaptations in lipid metabolism of bovine adipose tissue in lactogenesis and lactation. J. Lipid Res. 27:150-157.

Mosley, S. A., E. E. Mosley, B. Hatch, J. I. Szasz, A. Corato, N. Zacharias, D. Howes, and M. A. Mcguire. 2007. Effect of varying levels of fatty acids from palm oil on feed intake and milk production in Holstein cows. J. Dairy Sci. 90:987-993.

NRC. 2001. Nutritional Requirements of Dairy Cattle. 7th rev. ed. Natl. Acad. Sci., Washington, DC.

Pethick, D. W., and F. R. Dunshea. 1993. Fat metabolism and turnover. Pages 291-311 in Quantitative Aspects of Ruminant Digestion and Metabolism. J. M. Forbes and J. France, ed. CAB International, Wallingford, UK.

Piantoni, P., A. L. Lock, and M. S. Allen. 2013. Palmitic acid increased yields of milk and milk fat and nutrient digestibility across production level of lactating cows. J. Dairy Sci. 96:7143-7154.

Pires, J. A., A. H. Souza, and R. R. Grummer. 2007. Induction of hyperlipidemia by intravenous infusion of tallow emulsion causes insulin resistance in Holstein cows. J. Dairy Sci. 90:2735-2744

Rico, D. E., Y. Ying, and K. J. Harvatine. 2014a. Effect of a highpalmitic acid fat supplement on milk production and apparent total-tract digestibility in high- and low-milk yield dairy cows. J. Dairy Sci. 97:3739-3751.

Rico, J. E., M. S. Allen, and A. L. Lock. 2014b. Compared with stearic acid, palmitic acid increased the yield of milk fat and improved feed efficiency across production level of cows. J. Dairy Sci. 97:1057-1066.

Rico, J. E., V. V. R. Bandaru, J. M. Dorskind, N. J. Haughey, and J. W. McFadden. 2015. Plasma ceramides are elevated in overweight Holstein dairy cows experiencing greater lipolysis and insulin resistance during the transition from late pregnancy to early lactation. J. Dairy Sci. 98:7757-7770.

Saed Samii, S., J. E. Rico, A. T. Mathews, C. L. Orndorff, A. D. Davis, and J. W. McFadden. 2015. Comparison of the RQUICKI estimate of insulin sensitivity with glucose and insulin tolerance in periparturient dairy cows. J. Dairy Sci. 98(Suppl. 2):144. (Abstr.)

Schoenberg, K. M., R. M. Ehrhardt, and T. R. Overton. 2012. Effects of plane of nutrition and feed deprivation on insulin responses in dairy cattle during late gestation. J. Dairy Sci. 95:670-682.

Steele, W. 1969. The effects of dietary palmitic and stearic acids on milk yield and composition in the cow. J. Dairy Res. 36:369-373. 
Storry, J. E., A. J. Hall, and V. W. Johnson. 1973. The effects of increasing amounts of dietary tallow on milk-fat secretion in the cow. J. Dairy Res. 40:293-299.

Summers, S. A. 2006. Ceramides in insulin resistance and lipotoxicity. Prog. Lipid Res. 45:42-72.

Tylutki, T. P., D. G. Fox, V. M. Durbal, L. O. Tedeschi, J. B. Russell, M. E. Van Amburgh, T. R. Overton, L. E. Chase, and A. N. Pell. 2008. Cornell Net Carbohydrate and Protein System: A model for precision feeding of dairy cattle. Anim. Feed Sci. Technol. 143:174-202.

Ulberth, F., and F. Schrammel. 1995. Accurate quantitation of short-, medium-, and long-chain fatty acid methyl esters by split-injection capillary gas-liquid chromatography. J. Chromatogr. A 704:455463.

van Knegsel, A. T. M., H. Van Den Brand, J. Dijkstra, W. M. Van Straalen, R. Jorritsma, S. Tamminga, and B. Kemp. 2007. Effect of glucogenic vs. lipogenic diets on energy balance, blood metabolites, and reproduction in primiparous and multiparous dairy cows in early lactation. J. Dairy Sci. 90:3397-3409.

Van Soest, P. J., J. B. Robertson, and B. A. Lewis. 1991. Methods for dietary fiber, neutral detergent fiber, and nonstarch polysaccharides in relation to animal nutrition. J. Dairy Sci. 74:3583-3597.
Wang, J. P., D. P. Bu, J. Q. Wang, X. K. Huo, T. J. Guo, H. Y. Wei L. Y. Zhou, R. R. Rastani, L. H. Baumgard, and F. D. Li. 2010. Effect of saturated fatty acid supplementation on production and metabolism indices in heat-stressed mid-lactation dairy cows. J. Dairy Sci. 93:4121-4127.

Warntjes, J. L., P. H. Robinson, E. Galo, E. J. DePeters, and D. Howes. 2008. Effects of feeding supplemental palmitic acid (C16:0) on performance and milk fatty acid profile of lactating dairy cows under summer heat. Anim. Feed Sci. Technol. 140:241-257.

Wildman, E. E., G. M. Jones, P. E. Wagner, and R. L. Boman. 1982. A dairy cow body condition scoring system and its relationship to selected production characteristics. J. Dairy Sci. 65:495-501.

Wright, T. C., J. P. Cant, and B. W. McBride. 2002. Inhibition of fatty acid synthesis in bovine mammary homogenate by palmitic acid is not a detergent effect. J. Dairy Sci. 85:642-647.

Zachut, M., H. Honig, S. Striem, Y. Zick, S. Boura-Halfon, and U. Moallem. 2013. Periparturient dairy cows do not exhibit hepatic insulin resistance, yet adipose-specific insulin resistance occurs in cows prone to high weight loss. J. Dairy Sci. 96:5656-5669. 